\title{
Japanese Work Style Reformation and Its Impact on Large Japanese Companies
}

\author{
Hideki Takei (Corresponding author) \\ Dept. of Information Technology \& Administrative Management, Central Washington \\ University \\ 400 E University Way, Ellensburg, WA 98926, USA \\ E-mail: hideki.takei@cwu.edu
}

Received: Dec. 28, 2021 Accepted: Feb. 10, 2022 Published: March 6, 2022

doi:10.5296/ijssr.v10i1.19398ＵRL: https://doi.org/10.5296/ijssr.v10i1.19398

\begin{abstract}
The labor shortage in Japan will be 6.4 million by 2030 due to a continuously declining birth rate and inadequate job opportunities for homemakers, retirees, and foreigners. The shortage will destroy the sustainability of the Japanese economy without prompt action. The Japanese government revised labor laws to let Japanese companies solve the future labor shortage. In 2020, large Japanese companies started following the revised laws. This paper analyzed the Japanese companies' reactions to the enforcement. Based on the analyses, we developed five suggestions that may be challenging but possible for Japanese companies to maintain competitive advantages and operational sustainability.
\end{abstract}

Keywords: labor law, work style reformation, Japanese management 


\section{Introduction}

The labor shortage in Japan will be 6.4 million by 2030 due to a continuously declining birth rate and inadequate job opportunities for homemakers, retirees, and foreigners. The shortage will destroy the sustainability of the Japanese economy without prompt action. The Japanese government forced Japanese companies to solve the future labor shortage by revising labor laws. The revision was completed in 2019 and enforced on large Japanese companies in 2020. There are two major pieces of research about companies' reactions to the revised labor laws. In this paper, we analyze the research results to find out the challenges of Japanese companies. Then, we make practical suggestions to ease the challenges to solve the labor shortage.

\section{Japan's 2030 Problem}

The Japanese government estimates the labor shortage in 2025 will be 5.8 million. By 2030, it will be 6.4 million due to a continuously declining birth rate and inadequate job opportunities for homemakers, retirees, and foreigners. If the shortage happens, the sustainability of the Japanese economy will significantly decrease. The labor shortage will almost certainly happen regardless of the Japanese economic cycles without prompt action because demographic and systemic problems cause this shortage. The Japanese government has taken leadership to prevent the labor shortage or "the 2030 problem" (NRI1, 2015; MHLW1, 2020).

The Japanese government's major action was to revise the current labor law to let Japanese companies prevent the 2030 problem. The first goal of the revision is to force Japanese companies to develop flexible working systems to access the untapped workforce to increase labor and optimize employees' work-life balance to increase the birth rates. The second goal is to force them to improve per-employee productivity and operational efficiency by banning excessive overtime and mandating paid holidays (NRI1, 2015; NRI2, 2015; Yamada, 2019).

In 2019, the Japanese government revised the current labor law to introduce the work style reformation (WSR) to Japanese companies to improve per-worker productivity and flexible working styles by 2030. The government asked large Japanese companies to comply with it from April 2020 (NRI1, 2015; NRI2, 2015; Yamada, 2019; MHLW1, 2020).

\section{The Work Style Reformation}

WSR aims at solving labor shortage issues by requiring fewer workers to do the same tasks by improving per-worker productivity. As it will shorten work hours, young workers will have more time to care for their children. As a result, we can expect an increasing Japanese birth rate as young Japanese workers will have enough time to parent their children (MHLW2, 2019; MHLW3, 2019). Improved per-worker productivity will let them earn the same salary without excessive overtime. Therefore, they can maintain the same living standard without overtime compensations (MHLW2, 2019; MHLW3, 2019; Yamada, 2019).

WSR forces Japanese companies to access and secure unutilized workers who have not worked due to mismatched working styles. For example, many housekeepers and retirees 
cannot work five days a week from eight to five even if they have the competence and skills to work (MHLW2, 2019; MHLW3, 2019; Yamada, 2019). Japanese companies need to introduce more flexible working styles such as telecommuting, flextime, off-peak commuting, and short hour working for the untapped and potentially productive workers.

When the Japanese government revised the labor law, The Japan Business Federation suggested all Japanese companies change the organizational culture towards more diversity and inclusivity to implement and utilize flexible working styles. According to the suggestions, regardless of employment and working styles, they must treat all employees respectfully and equally. Otherwise, the untapped but highly competent workers will not come and stay in the organizations (Keidanren, 2017).

Many business executives and scholars agreed with the suggestion for the successful implementation of WSR. They said that Japanese companies must get out of the Japanese management systems, which have produced workaholics through labor-intensive working environments, excessive overtime, poor compensation structures, employee loyalty to companies, and exclusivity in company communities (Keidanren, 2017; Yamada, 2019).

Also, they warned Japanese companies to have more open-minded values and attitudes to accept newcomers with various backgrounds and expertise, new ways of business, and digital transformations for higher operational efficiency. Especially, the open-minded attitudes towards the digital transformation are essential to solving current hostile attitudes and resistance to the digital transformation and implementations of more flexible work styles (Keidanren, 2017; Hondaka, 2019).

\section{The Revised Labor Law}

The revised Japanese labor law forces Japanese companies to shorten work hours by illegalizing overtime work longer than 45 hours per month. Additionally, it forces them to let their workers take all paid holidays. It also indirectly forces them to implement efficient operating systems to improve employee productivity. Especially, the Japanese government expects real digital transformations in operations to maintain productivity improvement without excessive overtime work (MHLW2, 2019; MHLW3, 2019).

The revised law mandates the equal pay for equal work policy to eliminate unfair compensations between full-time and contracted workers who do the same task. The equal pay policy forces Japanese companies to give up on "generalists" who do everything companies ask. They have started developing well-defined job descriptions and specifications to hire qualified and productive workers as "specialists" (MHLW2, 2019; MHLW3, 2019).

The equal pay policy allows Japanese companies to implement flexible work styles to recruit housemakers, retirees, and foreigners who have not been able to work with the traditional eight-to-five onsite work style. The Japanese government expects that implementing flexible work styles for untapped workforces will also transform very exclusive organizational cultures into more diversified and inclusive ones (MHLW2, 2019; MHLW3, 2019).

The Japanese government assumes that the shortened work hours and the equal pay policy 
will motivate Japanese companies to offer continuous training in career advancement and outplacement to maintain high labor productivity. It will also enrich the Japanese labor market with more capable and productive workforces (MHLW2, 2019; MHLW3, 2019).

Finally, the revised law strengthens the Labor Standards Inspection Office's authority to monitor company operations and enforce severer penal regulations on them (MHLW2, 2019; MHLW3, 2019).

\section{Large Companies' Reactions to the Revised Labor Law}

In 2020, Deloitte Tohmatsu Consulting (DTC) and HR Research Institute (HRI) conducted surveys about companies' reactions to the revised law. According to published survey results, DTC surveyed 277 companies while HRI studied 194 companies (Deloitte, 2020; HR-Souken, 2020).

According to the survey results, almost all companies immediately banned overtime and reduced monthly work hours. They also forced employees to take more than five days of paid vacations to improve their work-life balance. As shortened work hours and increased paid vacation created many unfinished jobs, they started improving operating processes and systems to increase operational efficiency and productivity. Especially, digital transformation with advanced information technology and automation was a significant way of improving operational efficiency and employees' productivity. Finally, to complete the accumulated unfinished jobs, they quickly implemented a teleworking style to recruit female workers who cannot work in a traditional eight to five onsite work style.

According to the survey results, observed benefits were the progress of digital transformations in operations and systems, higher employee job satisfaction and retention, and increased job placement of women, particularly housewives. On the other hand, the results show serious issues such as failures in improving operational efficiency and per-employee productivity (Deloitte, 2020; HR-Souken, 2020).

The results also reported their employees' unwillingness to take paid vacations as they worried about the accumulated unfinished jobs. For the same reason, they resisted the elimination of overtime. However, the reports pointed out that another reason for the resistance was employees' unhappiness from significantly lower incomes by losing overtime compensations. Finally, the results showed that Japanese companies failed to develop operational systems to introduce a wide variety of flexible work styles to recruit housewives and other untapped competent workers, including foreign professionals (Deloitte, 2020; HR-Souken, 2020).

\section{Analysis}

We began our analysis with an assessment of the observed benefits. While digital transformation is great news for Japanese companies, we must check whether the progress is real or superficial. Generally, digital transformation tends to increase operational efficiency, employees' productivity, and variations of work styles (PRTimes, 2020; Yonemura, 2020). Therefore, if Japanese companies observed these benefits from the digital transformation, we 
could say the progress of transformation is real and, therefore, beneficial for Japanese companies.

According to the survey results, Japanese companies faced fierce resistance to digital transformations, especially by middle managers (Deloitte, 2020; HR-Souken, 2020). Many consultants pointed out that the resistance occurred because they did not have champions leading digital transformations and technology-savvy employees who could use advanced digital technologies. Also, none offered appropriate employee training to prepare their employees for digital transformation (Hondaka, 2019; Deloitte, 2020; HR-Souken, 2020; Fce-pat, 2021; Kiddimatomete, 2021). These show the digital transformation seemed doomed to failure.

Most Japanese companies did not offer employees technical training for digital transformation. While they have focused on OJT for technical skill acquisitions, they could not offer OJT for digital transformation as they did not have highly digitized employees who could train other employees. Additionally, they have more focused on developing ideal company community members. Instead of offering continuous training for career development, skill development, and an innovative mindset, they have offered training to strengthen employee loyalty to the companies and company communities, the mentality for hardworking without holidays, and "common sense" in the company communities. After all, Japanese employees have not been trained to be innovative and digital savvy to improve their productivity (Abe, 2021).

Also, the result showed Japanese companies' failures in improving per-employee productivity and flexibility of work styles even if they said the digital transformation was progressing (Hondaka, 2019; Deloitte, 2020; HR-Souken, 2020; Fce-pat, 2021; Kiddimatomete, 2021). Poor per-employee productivity has been a serious problem. In reality, Japanese per-employee productivity has been the worst among advanced countries (HRBrain, 2020; Nice2meet, 2020).

Besides poor digital transformation, Japanese employees were not even trying to improve their productivity to work longer hours. Earning overtime compensation has been important for them to maintain their living standards. As Japanese companies had assigned seven employees to ten employees' tasks, they had taken considerable overtime compensation into account when they decided the base salary (Ohashi, 2009; Nishimura, 2020). Therefore, without sufficient base salary, employees would see a deterioration of living standards without overtime. This caused serious resistance to the digital transformation (Hondaka, 2019; Akizawa, 2020; DC, 2020; Korosuke, 2020; Manegy2, 2020).

The virtue of hardworking in company communities caused serious resistance against improving productivity through digital transformation. For them, working fewer hours with advanced information technology violates the virtue. Many veteran managers worry if the digital transformation will make employees lazy and less loyal to the company (Hondaka, 2019; Kumashiro, 2020).

Other benefits were better employee job satisfaction and retention due to fewer working 
hours and more paid holidays. However, these benefits seem to be short living as long as Japanese companies do not increase base salary and change the virtue of hardworking in the company community. They showed higher job satisfaction and retention because they simply enjoyed good rest even if they sacrificed their living standards. They had been completely exhausted physically and mentally (Sbbit, 2017; Shijizero, 2018; Manegy1, 2019; HRM-Service, 2020; Kinchaku, 2020). Also, a higher retention rate might come from the COVID19 pandemic that made job searches practically impossible (HRM-Service, 2020; Katani, 2020; Okan-media, 2021).

Once they take a good rest, the high job satisfaction may not continue. This assumption was proven in the results. They already started demanding long work hours, worrying about accumulated unfinished jobs, and degrading living standards. In fact, many started asking for excessive overtime to complete the unfinished jobs and bring back the living standard (HRM-Service, 2020; Mhlw4, 2020). Again, unless Japanese companies increase base salary, no overtime and many paid holidays will not maintain high job satisfaction and retention (Manegy1, 2019; Yayoi-kk, 2019; Kinchaku, 2020).

The last benefit was increased recruitment of females, particularly housewives. While this is good news, we must be careful about this outcome. The improved work flexibility to recruit housewives may not mean the improved flexible work style to recruit untapped productive workers and professionals (Maeda, 2019; JCO, 2020).

Japanese companies had looked for housewives for simple jobs long before WSR started. Their preferences have been housewives with previous work experiences, technical know-how, no motivation for career advancement, skills to be a member of company communities, and flexibility for work styles and hours (Maeda, 2019). Japanese companies' real motivation might be to finish accumulated jobs that employees used to finish through overtime work (Maeda, 2019; JCO, 2020). Fortunately, they could recruit job-seeking housewives much easier by offering them telecommuting work styles which they had to implement during the COVID19 pandemic to sustain their operations (Maeda, 2019; JCO, 2020). We also need to notice that recruiting housewives may not mean better diversity and inclusivity of the organization (Maeda, 2019; JCO, 2020).

Introducing flexible work styles and improving diversity and inclusion are facing serious resistance in company communities, which have been exclusive to full-time employees. The community members are supposed to be full-time employees who will work together in the traditional onsite work style. The traditional community members may not even accept telecommuting full-time employees as community members. Many community members have not supported flexible work styles as these will bring many part-time employees and contractors to disturb the harmony of the community (JCO, 2020; Itscom, 2020; Kaikatsu, 2020; MAG, 2020; Talknote, 2020).

Interestingly, company community members have worried if many foreign employees will join the community through flexible work styles. However, they may not need to worry about it as foreign employees may not take advantage of the flexible work styles in Japanese companies. In addition to language barriers, Japanese companies are not attractive because 
they cannot expect career advancement through work. Japanese companies usually do not offer professional training for career advancement, competitive salary and compensation, and sufficient paid vacations (Bridgers, 2020). Similarly, many retirees may not work for Japanese companies because of their incapability to deal with advanced information technology and the community's exclusivity (Shifop, 2020; Talknote, 2020).

\section{Suggestions}

Japanese companies must implement WSR to solve the 2030 labor shortage and sustain organizational competitiveness. Based on our analyses, we made five suggestions for them.

First, they must develop well-defined job descriptions of any position, and at the same time, they must specify and standardize the operational procedures and systems of each position. Then, transform generalists into specialists who know clear authorities and responsibilities of their roles. They need to continuously offer job-specific training to let the specialists improve their skills and productivity.

Second, they must give up the current base salary structure, which considers a large portion of overtime compensation. They must introduce a more position-specific base salary structure. The new base salary structure will allow employees to maintain living standards without overtime compensation and appropriate work-life balance. Also, it will allow employers to implement the equal pay policy to fully extend flexible work styles for more diversified and competent labor pools.

Third, they need to seriously digitize their operations by having "champions" who are high-ranked managers leading the digital transformation. The champions will change employees' attitudes towards the digital transformation to eliminate unhealthy resistance from, especially, middle managers. The champions must work with human resource departments to offer employees appropriate hardware and software training.

Fourth, they must have transformational leaders to change the fundamental values of company communities (SupLab, 2020). Working long hours must not be a virtue any longer. Employees must respect diversity and inclusivity in work styles and approaches no matter being full-time or part-time employees. They must respect employees who try to improve productivity to shorten work hours with the same outcomes. Employees must maintain a work-life balance to enjoy public and private life, and they need to take enough rest to be creative and productive. Companies must educate all employees about labor law and workers' rights to protect themselves from unlawful working conditions.

Finally, top management must show new values to their stakeholders, especially customers (Amemiya, 2016; Murata, 2017; Ouchi, 2017). They must let customers who ask for unreasonable services know that they will only offer services matching the costs. They must educate them now because our suggestions require understanding and collaboration. Transforming customer values and attitudes has a similar importance to transforming the company community values. 


\section{Conclusions}

WSR is mandatory for Japanese companies to maintain powerful competitiveness in the global market. Japanese companies must improve employee productivity by digitizing their operations. They must train their employees to work in a digitally transformed work environment. They must transform their organizations from the traditional Japanese company community to a more diversified and inclusive working community. They develop well-defined job descriptions to recruit competent workers, extend flexible work styles, and offer competitive salaries without overtime compensation to maintain employees' work-life balance.

Our suggestions may be challenging for Japanese companies. However, these are not impossible, and all they need is powerful determination in transforming their organizational values for the future.

\section{References}

Abe, Y. (2021, May 12). roudou-pro. Retrieved May 2021, from Equal pay for equal work https://roudou-pro.com/columns/135/

Akizawa, M. (2020, September 3). help-you. Retrieved September 2020, from Low labor productivity in Japan https://help-you.me/blog/roudou_0516/

Amemiya, S. (2016, November 22). Toyokeizai. Retrieved December 2020, from Customer Outrage https://toyokeizai.net/articles/-/145385

Bridgers. (2020, April 8). bridgers. Retrieved August 2020, from Employment issues for foreign workers https://bridgers.asia/recruit/gaikokujinroudousya01/

DC. (2020). Douitsu-Chingin. Retrieved August 2020, from Equal pay for equal work and corporate response https://douitsu-chingin.com/about/correspond/

Deloitte. (2020, February 5). Deloitte. Retrieved July 2020, from survey on the actual $\begin{array}{lllll}\text { situation of } & \text { work } & \text { reform } & 2020\end{array}$ https://www2.deloitte.com/content/dam/Deloitte/jp/Documents/about-deloitte/news-releases/j p-nr-nr20200205.pdf

Fce-pat. (2021, May 10). Fce-pat. Retrieved May 2021, from Digital transformation that is the key to realizing work style reform https://fce-pat.co.jp/magazine/1509/

Hondaka, S. (2019, August). bcm. Retrieved May 2020, from Digital transformation and work style reform https://www.bcm.co.jp/solution-now/cat-solution-now/2019-08_2192/

HR-Souken. (2020, July 1). HR-Souken. Retrieved July 2020, from Questionnaire on work style reform https://hr-souken.jp/research/936/

HRBrain. (2020, April 19). hrbrain. Retrieved August 2020, from Japan has the lowest labor productivity in developed countries https://www.hrbrain.jp/media/labor-management/labor-productivity1 
HRM-service. (2020, February 20). hrm-service. Retrieved April 2020, from Let's grasp the actual situation of work style reform by employee satisfaction survey https://www.hrm-service.net/column/article107/

Itscom. (2020, January 5). itscom. Retrieved March 2020, from Telework failure example https://www.itscom.co.jp/forbiz/column/remotework/432/

JCO. (2020). Japan Cabinet Office. Retrieved March 2021, from Flexible work styles and work style reforms under the spread of infectious diseases https://www5.cao.go.jp/j-j/wp/wp-je20/h02-03.html

Kaikatsu. (2020, July 13). kaikatsu. Retrieved August 2020, from The main reasons for failure to reform work styles https://www.kaikatsu.jp/column/012439.html

Katani, K. (2020, May 13). itmedia. Retrieved August 2020, from The reason why the COVID crisis destroys the irrational "Company Community" in Japanese companies https://www.itmedia.co.jp/business/articles/2005/13/news029.html

Kddimatomete. (2021, August 20). Kddimatomete. Retrieved September 2021, from Relationship between work style reform and digital transformation https://www.kddimatomete.com/magazine/210820164020/

Keidanren. (2017, September). Keidanren. Retrieved March 2020, from Promote work style reforms https://www.keidanren.or.jp/policy/2017/072.pdf

Kinchaku. (2020). Kinchaku. Retrieved May 2020, from Japan needs to change workstyle https://www.kinchaku.com/blog/japan-needs-to-change-workstyle

Korosuke. (2020, March 27). bukiyoublog. Retrieved August 2020, from Reasons for Low Labor Productivity of Japan https://bukiyoublog.com/opinion-reason-low-productivity

Kumashiro, T. (2020, June 5). newspicks. Retrieved August 2020, from In Japanese society, the virtue of "with everyone" is the source of trust rather than the outcome https://newspicks.com/news/4966986/

Maeda, Y. (2019, November). Current Situation and Challenges of Working Women. The Economic Prism (181). Retrieved from https://www.sangiin.go.jp/japanese/annai/chousa/keizai_prism/backnumber/h31pdf/20191810 2.pdf

MAG. (2020). mag. Retrieved August 2020, from Flexible Way of Working https://mag.jws-japan.or.jp/hint/work/flexible-way-of-working/

Manegy1. (2019, October 11). Manegy. Retrieved April 2020, from One in three companies has increased the number of employees leaving their jobs due to "work style reform" https://www.manegy.com/news/detail/1709

Manegy2. (2020, March 14). manegy. Retrieved August 2020, from Wage system with overtime work https://www.manegy.com/news/detail/2288 
MHLW1. (2020). Japanese Ministry of Health, Labor, and Welfare White Paper. Retrieved August 2020, from Recent socio-economic changes and household trends https://www.mhlw.go.jp/wp/hakusyo/kousei/08/dl/04.pdf

MHLW2. (2019). Japan Ministry of Health, Labor and Welfare. Retrieved March 2020, from Work style reform https://www.mhlw.go.jp/content/000335765.pdf

MHLW3. (2019, October). Japan Ministry of Health, Labor and Welfare. Retrieved March 2020, from Handbook on work style reform related laws https://www.pref.ibaraki.jp/doboku/kanri/kensetsu/menue/kasseikajigyou/documents/hataraki katakaikaku.pdf

MHLW4. (2020). Mhlw. Retrieved August 2020, from Relationship between efforts aimed at work style reform and turnover rate, etc. https://www.mhlw.go.jp/stf/wp/hakusyo/roudou/19/backdata/2-2-35.html

Murata, A. (2017, November 21). shares. Retrieved December 2020, from Long working hours and customer demands https://www.shares.ai/lab/roumu/1234985

Nice2meet. (2020, January 31). nice2meet. Retrieved August 2020, from The difference between productivity and efficiency in work https://www.nice2meet.us/the-difference-between-prodictivity-and-efficiency-in-work

Nishimura, Y. (2020). fukuoka-roumu. Retrieved August 2020, from Work Style Reformation https://www.fukuoka-roumu.jp/workstyle/choujikan

NRI1. (2015, April). Creation of Intellectual Property. Retrieved March 2020, from Structural challenges facing Japan in 2030 https://www.nri.com/-/media/Corporate/jp/Files/PDF/knowledge/publication/chitekishisan/20 15/04/cs20150403.pdf?la=ja-JP\&hash=B0927A2485E90BD14BF0C7F4CEA9B0E068575C 87

NRI2. (2015, May). Creation of Intellectual Property. Retrieved March 2020, from What Japanese society should be in 2030 from the perspective of consumers https://www.nri.com/-/media/Corporate/jp/Files/PDF/knowledge/publication/chitekishisan/20 15/05/cs20150507.pdf?la=ja-JP\&hash=0B481B8A37E63E54B271C15D2DA2D2F142B1503 9

Ohashi, I. (2009, December). Japan's minimum wage system. Japan Labor Survey Journal (593). Retrieved from https://www.jil.go.jp/institute/zassi/backnumber/2009/12/pdf/004-015.pdf

Okan-media. (2021, July 16). Okan-media. Retrieved July 2021, from https://okan-media.jp/workstyle-reform-simply

Ouchi, S. (2017, July 10). recruit-ms. Retrieved December 2020, from Excessive customer focus is the root cause of long working hours https://www.recruit-ms.co.jp/issue/interview/0000000584/?theme=productivity 


\section{Macrothink}

International Journal of Social Science Research

ISSN 2327-5510 2022, Vol. 10, No. 1

PRTimes. (2020, August 24). prtimes. Retrieved October 2020, from Survey of work style awareness in COVID-19 pandemic https://prtimes.jp/main/html/rd/p/000000026.000045221.html

Sbbit. (2017, November 22). Sbbit. Retrieved March 2020, from Reasons why half of employees are "not satisfied" due to work style reform https://www.sbbit.jp/article/cont1/34247

Shifop. (2020, March 9). shifop. Retrieved August 2020, from IT solves the problems caused by flexible working styles! https://www.shifop.jp/column/c228

Shijizero. (2018, May 15). shijizeo. Retrieved December 2020, from Why do Japanese Company Communities Destroy Creative Employees? https://www.shijizero.jp/archives/n6029

SupLab. (2020, May 22). suplab. Retrieved August 2020, from Eight efforts to eliminate long working hours https://suplab.jp/longworkhours225002/

Talknote. (2020). talknote. Retrieved March 2021, from What will change in "work style reform" after all? https://talknote.com/magazine/work-style-reform/

Yamada, H. (2019). How to deal with the rapidly increasing number of foreign labor. JRI Review, 10(71). Retrieved April, 2020, from https://www.jri.co.jp/MediaLibrary/file/report/jrireview/pdf/11444.pdf

Yayoi-kk. (2019, January 18). Media Yayoi-kk. Retrieved March 2020, from Increasing employee satisfaction is the goal of "work style reform" https://media.yayoi-kk.co.jp/business/8212/

Yonemura, K. (2020, August 24). Impact of Corona on work style reforms. Finance and Financial Business. Retrieved September 2020, from https://www.murc.jp/wp-content/uploads/2021/06/contribution2020-05_04.pdf

\section{Appendix A}

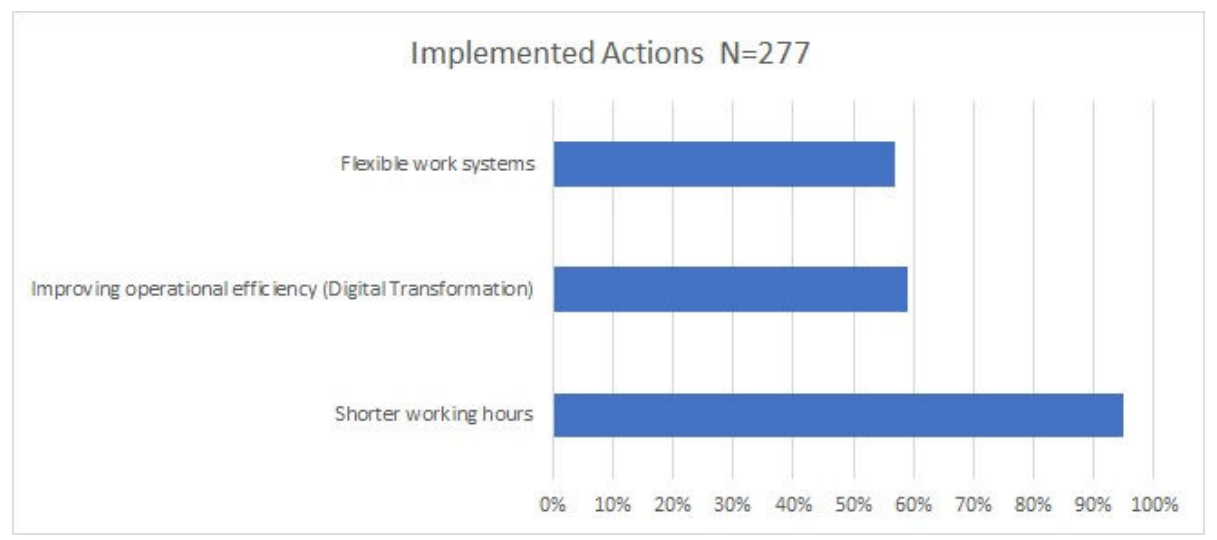

Figure 1. Implemented actions 


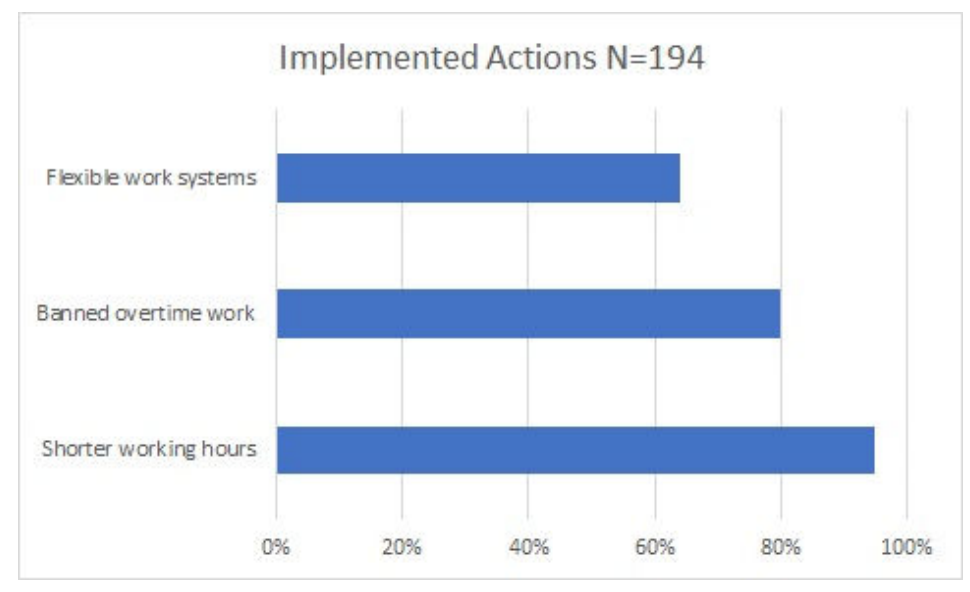

Figure 2. Implemented actions

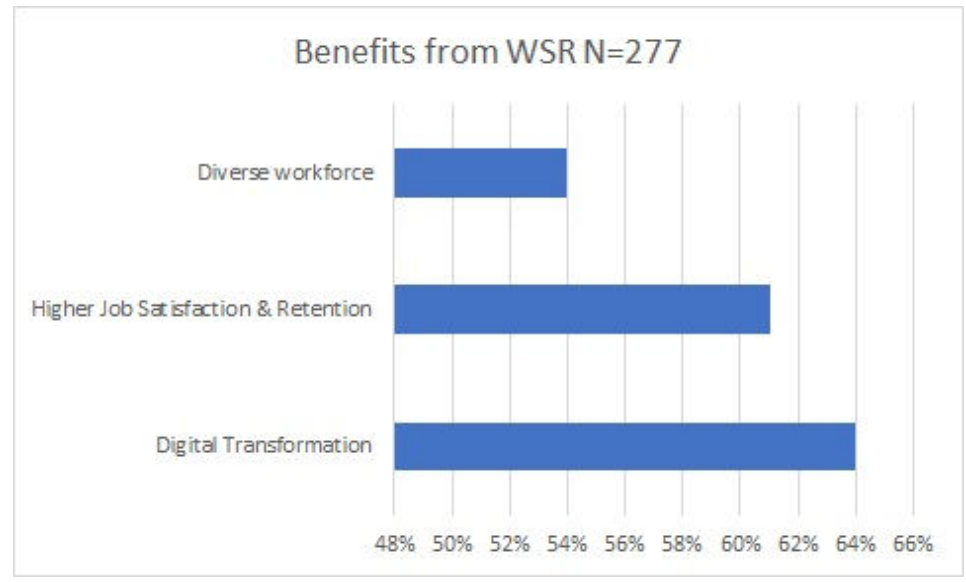

Figure 3. Benefits from WSR

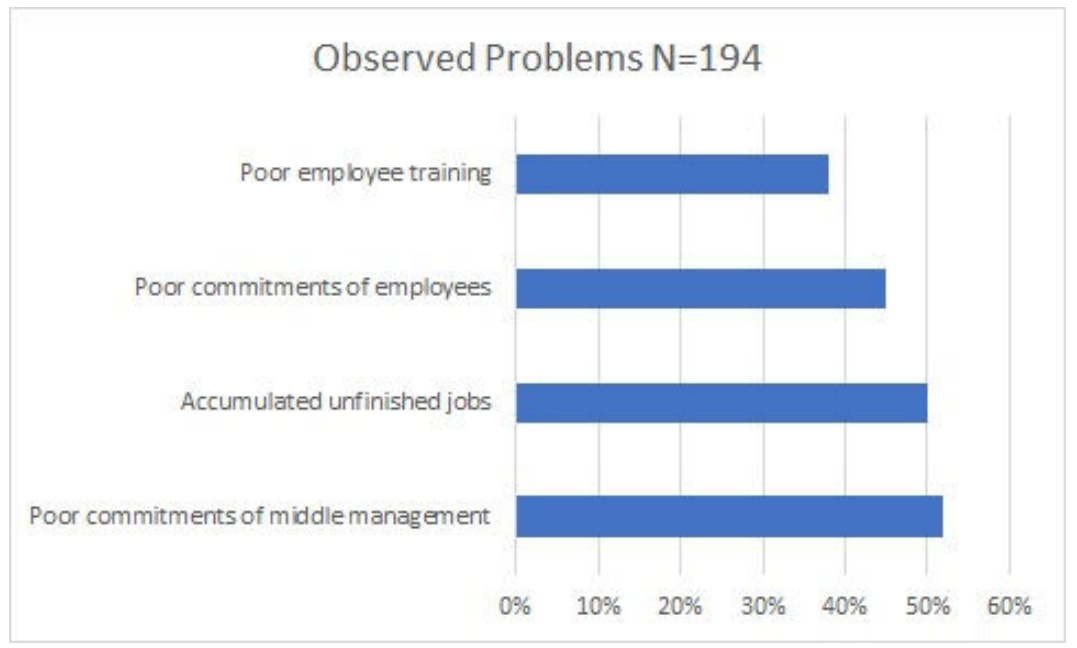

Figure 4: Observed problems 


\section{Macrothink}

International Journal of Social Science Research

ISSN 2327-5510

\section{Copyrights}

Copyright for this article is retained by the author(s), with first publication rights granted to the journal.

This is an open-access article distributed under the terms and conditions of the Creative Commons Attribution license (http://creativecommons.org/licenses/by/4.0/). 